\title{
Present status of clofibrate therapy in ophthalmology
}

\author{
J. NOLAN AND J. F. GULLEN \\ Department of Ophthalmology, Royal Infirmary, Edinburgh
}

Clofibrate reduces serum lipid levels, interferes with blood clotting, and may possibly alter aqueous humour dynamics. It has been used in the treatment of hard retinal exudates, retinal vascular occlusion, lipidosis oculi, and certain types of glaucoma.

\section{Pharmacology}

Clofibrate is ethyl chlorophenoxyisobutyrate. It was first introduced in 1962 combined with androsterone as "Atromid", but subsequently it was found that clofibrate alone was equally active and it is now marketed uncombined as "Atromid-S". Although the picture is incomplete, certain features of its metabolism are becoming clear. Clofibrate is administered by mouth, being rapidly absorbed and hydrolysed to the acid (CPIB) by non-specific esterases. $750 \mathrm{mg}$. three times a day are required to maintain the optimum serum level of $100 \mu \mathrm{g} . / \mathrm{ml}$. The drug remains extra-cellular and is carried in the serum, over 98 per cent. being bound to serum albumin. It does not become localized in body tissue and is excreted solely via the kidneys, having a half life in vivo of 12 hours. The preference of serum albumin for CPIB results in the displacement of other acidic substances including thyroxin, free fatty acids, and androsterone, so that the serum levels of these fall.

The displaced thyroxin accumulates in the liver, where it causes increased protein synthesis, a fall in the liver glycogen stores, increased cholesterol metabolism with excretion of cholesterol as bile acid, and increased breakdown of testosterone to androsterone, which has a direct cholesterol-lowering effect. The diminution of liver glycogen results in the utilization of free fatty acids for energy purposes so that less are available for lipid synthesis. In addition less circulating thyroxin is available to stimulate free fatty acid release from tissue stores. These factors cause lower serum lipid levels, as does the diminished serum carrying capacity for free fatty acids.

Clofibrate affects blood clotting by lowering serum fibrinogen, diminishing platelet stickiness and increasing fibrinolytic activity. These actions may be due to the fall in serum androsterone, since it has been shown that the administration of androsterone sulphate causes a rise in serum fibrinogen. In addition, Hume (1965) found a direct relationship between circulating thyroxin and fibrinogen levels, with an inverse relationship between thyroxin level and fibrolytic activity.

\section{Diabetic retinal hard exudates}

Before the introduction of clofibrate, it was known that a clearance of diabetic hard fundus exudates accompanied the hypolipaemic effect of a low fat diet (Van Eck, 1959), and therefore clofibrate appeared as a logical mode of therapy in this condition. Three major trials have now been carried out, all giving similar results. Duncan, Nolan, Ireland, Cullen, Clarke, and Oliver (1968) published an exhaustive account of a 3-year trial in Edinburgh; Houtsmuller ( 1967 ) described a 3-year double-blind trial in Rotterdam; and Harrold and Marmion (1966) performed a I 2-months' double-blind trial in Bristol. The Edinburgh series is continuing, and in the first 5 years 53 patients have been treated with clofibrate 
and 35 observed as controls for periods in excess of 12 months, with results which not only $\frac{0}{3}$ largely confirm the earlier findings (Table I) but also shed further light on the clinicalo effects of clofibrate. Thus, the institution of therapy in thirteen patients who developed macular exudates after being observed as controls for periods in excess of one year gave a mini-trial with built-in controls. Three of these patients subsequently showed a clearance of exudates in both eyes and four in one eye, in five the deterioration was halted in both $\frac{\overline{\bar{s}}}{\bar{\sigma}}$ eyes, and in only one has there been a continued increase in hard exudates. This provides $\mathbb{\Phi}^{\circ}$ more definite evidence than was hitherto available that the progressive increase in hard exudates in most cases of exudative diabetic retinopathy can be arrested and reversed by $\vec{\circ}$ clofibrate therapy. Again, clofibrate therapy has been stopped in fourteen patients because of complete clearance of exudates from the macular regions. The duration of therapy required for this clearance varied from 24 to $5^{6}$ months. These patients have $\frac{O}{0}$. since been followed up for periods ranging from 6 to 37 months. Four of them have showni increase in exudates again in both eyes and five in one eye. This increase became manifest $\overrightarrow{-}$ after periods ranging from 4 to 24 months. The changes induced by clofibrate are there- 0 fore not permanent but do appear to continue throughout the period of therapy. The remaining five patients have shown no further change in fundus appearances over periodsc of 9, 9, I5, 15, and 19 months respectively, and there does not appear to be any rebound effect of diabetic hard exudates after stopping treatment. In patients who respond to clofibrate, no escape phenomenon has been noted, and resistance to the drug does not seem $\vec{\bullet}$ to develop.

Table I Comparison of exudate results found in various series (see text) in percentage of total

\begin{tabular}{|c|c|c|c|c|c|c|c|c|}
\hline \multirow[t]{2}{*}{ Result } & \multicolumn{4}{|l|}{ Treated } & \multicolumn{4}{|l|}{ Control } \\
\hline & $\begin{array}{l}\text { Edinburgh } \\
5 \text { yrs }\end{array}$ & $\begin{array}{l}\text { Duncan } \\
\text { and others }\end{array}$ & Houtsmuller & $\begin{array}{l}\text { Harrold } \\
\text { and } \\
\text { Marmion }\end{array}$ & $\begin{array}{l}\text { Edinburgh } \\
5 \text { yrs }\end{array}$ & $\begin{array}{l}\text { Duncan } \\
\text { and others }\end{array}$ & Houtsmuller & $\begin{array}{l}\text { Harrold } \\
\text { and } \\
\text { Marmion }\end{array}$ \\
\hline $\begin{array}{l}\text { Improved } \\
\text { No change } \\
\text { Worse }\end{array}$ & $\begin{array}{r}49 \\
42 \\
9\end{array}$ & $\begin{array}{r}57 \\
39 \\
4\end{array}$ & $\begin{array}{l}69 \\
20 \\
\text { I I }\end{array}$ & $\begin{array}{r}43 \\
53 \\
4\end{array}$ & $\begin{array}{l}14 \\
66 \\
20\end{array}$ & $\begin{array}{l}16 \\
56 \\
28\end{array}$ & $\begin{array}{l}15 \\
37 \\
48\end{array}$ & $\begin{array}{r}4 \\
80 \\
16\end{array}$ \\
\hline Total eyes & 106 & 46 & 23 & 60 & 70 & 50 & 19 & 60 \\
\hline $\begin{array}{l}\text { Observation } \\
\text { period (yrs) }\end{array}$ & 5 & 3 & 3 & $\mathbf{I}$ & 5 & 3 & 3 & $\mathbf{I}$ \\
\hline
\end{tabular}

The haemorrhagic aspect of the retinopathy is completely unaffected for better or worse윽 by clofibrate therapy (Table II, opposite). This confirms the conclusions reached in the $\frac{7}{0}$ earlier studies.

Whilst these earlier studies have shown a slight but non-significant improvement in visual acuity with clofibrate therapy, our 5-year results indicate that this improvement may be $\mathcal{O}^{\circ}$ greater than previously recognized. Table II shows that 17 per cent. of treated patients $\tilde{\omega}$ improved by at least two parameters (Snellen or Near) compared with 3 per cent. of the control patients. There is evidence (Roth, 1969) that one of the earliest detectable changes in retinal function in diabetic retinopathy is a small scotoma and that this is reversible at first. This change may be due to a local patch of oedema occurring in the 0 deeper layers of the retina secondary to lipid thrombi in the smaller vessels as shown by $\vec{\oplus}$ Ghester and Banker ( 1967 ). Clofibrate appears able to reverse changes causing foveal impairment in at least some cases. Its mode of action in reducing diabetic hard fundus $\stackrel{D}{\circ}$ exudates, however, is still unknown (Duncan and others, I968). 
Table II Results after 5 years' observation (eyes)

\begin{tabular}{|c|c|c|c|c|c|c|c|c|c|}
\hline \multirow{2}{*}{$\begin{array}{l}\text { Symptoms } \\
\text { Results }\end{array}$} & \multicolumn{3}{|l|}{ Exudates } & \multicolumn{3}{|c|}{ Haemorrhages } & \multicolumn{3}{|c|}{ Visual acuity } \\
\hline & Improved & No change & Worse & Improved & No change & Worse & Improved & No change & Worse \\
\hline \multirow{2}{*}{$\begin{array}{l}\text { Treated } \\
\text { No. } \\
\text { Control }\end{array}$} & $5^{2}$ & 44 & 10 & o & 84 & 22 & 18 & 63 & 25 \\
\hline & 10 & $4^{6}$ & 14 & o & $5^{6}$ & 14 & 2 & 44 & 24 \\
\hline \multirow{2}{*}{$\begin{array}{c}\text { Treated } \\
\text { Per cent. } \\
\text { Control }\end{array}$} & 49 & $4^{2}$ & 9 & o & 79 & 21 & 17 & 60 & 23 \\
\hline & 14 & 66 & 20 & o & 80 & 20 & 3 & 63 & 34 \\
\hline
\end{tabular}

\section{Non-diabetic retinal hard exudates}

The success of clofibrate therapy in exudative diabetic retinopathy has encouraged its trial in certain other conditions which show very similar histological changes. These changes include packing of the middle and outer retinal layers with lipid material, some extracellular but most in lipid-laden macrophages, together with neovascularization, microaneurysms, hyalinization of the vessel walls, and destruction of adjacent nervous tissue. They occur in diabetic retinopathy, non-diabetic circinate retinopathy, and Coats's disease, and after retinal vein occlusion. A basic common factor of anoxia is postulated (Duke-Elder and Dobree, 1967).

Circinate retinopathy has been successfully treated with clofibrate by Vannas, Esilä, and Tuovinen (1968) in a number of patients with raised serum cholesterol and triglyceride levels, most of whom were also hypertensive. The exudates apparently diminished in all their patients and cleared completely in five.

A 66-year-old woman with Coats's disease has been under treatment in Edinburgh with clofibrate for 16 months. Figs $I$ and 2 show definite clearance of the exudates. The serum cholesterol has been reduced from 360 to $260 \mathrm{mg}$. per cent.

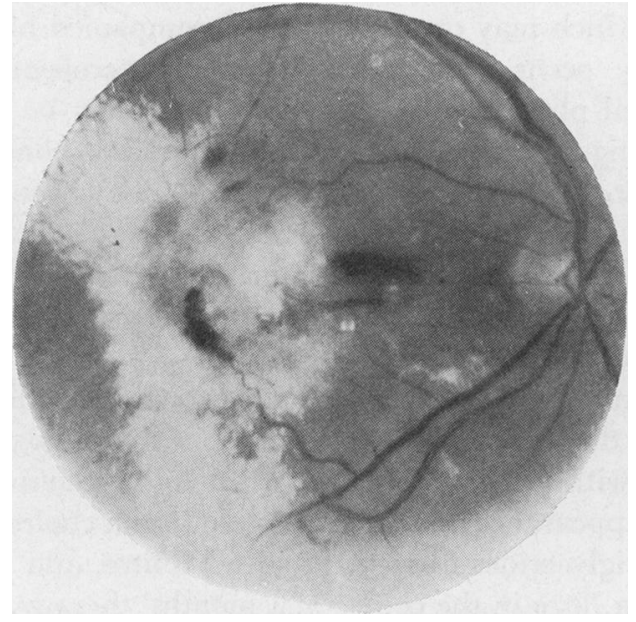

FI G. I Fundus of patient with adult Coats's disease before clofibrate therapy. Right eye

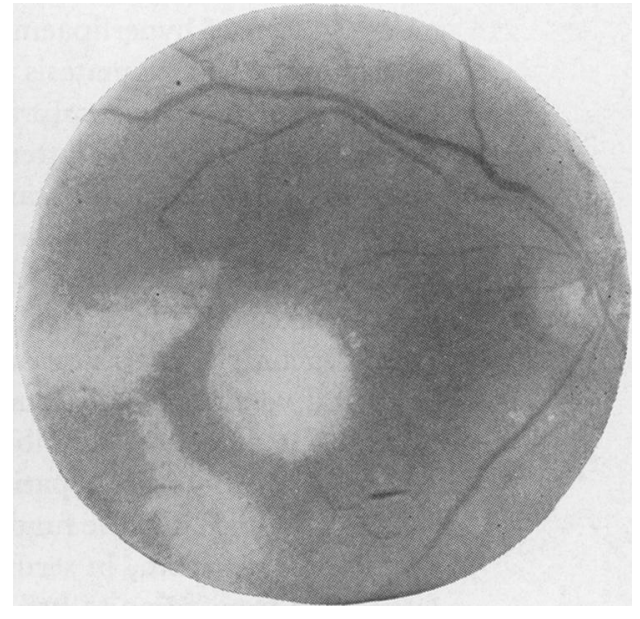

FIG. 2 Same fundus as Fig. I after 16 months' clofibrate therapy

Further trials of clofibrate in these other types of hard retinal exudate are indicated. 


\section{Retinal vascular occlusion}

The effects of clofibrate on blood clotting and fibrinolysis give grounds for its use in retinal vascular occlusion, although it is to be expected that, in an established vascular occlusion, too much retinal damage will have ensued to allow recovery when the blocked vessels recanalize. Clements, Elsby, and Smith (1968), in a double-blind trial, showed that clofibrate had no significant effect in retinal vein occlusion. There is strong eviderce that an established central retinal vein occlusion is usually accompanied by central retinal artery occlusion (Paton, Rubinstein, and Smith, I964; Hayreh, 1965), but a number of cases of clinical central retinal vein thrombosis occur in which normal visual acuity is still present when the patient is first seen. These patients also have good projection, and it seems likely that in these cases the central retinal artery is still patent. Here, clofibrate may prevent the subsequent occurrence of central retinal artery thrombosis and thus preserve central visual acuity. The likelihood that clofibrate would produce faster clearance of the hard exudates which are an aftermath of retinal vein occlusion is of purely academic interest and no studies have been done on the subject.

\section{Lipidosis}

Abnormally high concentrations of lipids in the blood may produce two types of ocular manifestation: lipaemia retinalis and xanthomatosis.

In lipaemia retinalis, fat in an emulsified form is present in the blood to a degree which alters its appearance on fundus examination. With a fat content of about $3.5 \mathrm{~g}$./100 ml., the peripheral fundus vessels appear milky and the arteries and veins indistinguishable. As the fat content rises, the larger vessels become involved until at about $10 \mathrm{~g}$. $/ \mathrm{r} 00 \mathrm{ml}$. the optic disc vessels become salmon-pink. Choroidal vessel involvement gives an ivory hue to the fundus.

In xanthomatosis, deposits of lipid occur in the tissues. This lipid accumulation may consist chiefly of cholesterol (hypercholesterolaemia) or of neutral fat (hyperlipaemia). Pure hypercholesterolaemia does not produce a cloudy serum and lipaemia retinalis is a manifestation of hyperlipaemia, which may or may not be accompanied by hypercholesterolaemia. Xanthomatosis may occur with either hypercholesterolaemia or hyperlipaemia. Excluding postprandial physiological rises, both types may be familial (idiopathic) or acquired, the latter being due to excessive fat mobilization in conditions such as diabetes, carcinomatosis, starvation, leukaemia, lipid nephrosis, or chronic alcoholism. Most cases of hyperlipaemia are acquired, and most cases of hypercholesterolaemia are familial. The commonest ocular manifestation of xanthomatosis is xanthelasma. Premature arcus senilis, lipid keratitis, and retinal xanthomata also occur. Woods and Duke (1963) include Coats's disease under this heading.

Both lipaemia retinalis and xanthomata associated with raised serum lipids could be N expected to respond to clofibrate therapy, and Cullen and Conacher (1965) reported the $\mathbb{\omega}_{\omega}$ successful treatment of a patient with idiopathic lipaemia retinalis. Clofibrate produced 0 a return to normal of the fundus appearance and a reduction in serum cholesterol from $653 \stackrel{\circ}{\circ}$ to $380 \mathrm{mg}$. per cent., in serum triglycerides from $5^{\circ}$ to $30 \mathrm{mM}$./litre, and in unesterified fatty acids from $\mathrm{I}, 620$ to $876 \mathrm{mEq}$./litre in the course of 4 months' therapy.

In essential hyperlipaemic xanthomatosis, clearance of all xanthomata with clofibrate therapy lasting 12 to 24 months was reported in twelve cases by Wahlin, Cramér, and Hood (1964), in five by Mishkel (1964), and in three by Borrie (1964a). In essential hypercholesterolaemic xanthomatosis, clofibrate therapy lasting 18 to 24 months resulted 
in clearance of all xanthomata in fourteen cases reported by Wahlin and others (1964), ten reported by Borrie (1964b), and six reported by Church (1964). Eyelid xanthelasma is easily and quickly treated by surgery and also responds well to light coagulation and to trichloracetic acid applications, though the latter are somewhat painful, but clofibrate offers an alternative treatment in view of its beneficial effects on the raised serum lipids and its ease of administration.

\section{Glaucoma}

Orbán, Hanisch, and Vereb (1966) found acute angle-closure glaucoma attacks to be associated with a rise in free fatty acids and serum viscosity, and accordingly treated attacks of angle-closure glaucoma in ten patients with a single oral dose of $\mathrm{I} \cdot 5 \mathrm{~g}$. clofibrate. The serum lipids fell and in eight cases the intra-ocular pressure returned to normal within 6 hours without any other treatment. This finding is worth further investigation, although it must be remembered that many attacks of angle-closure glaucoma resolve spontaneously and that any kind of stress causes a rise in serum lipids. In a second brief report, Orbán (1968) claimed good results in angle-closure, chronic simple, and secondary glaucoma with clofibrate therapy, but a detailed study has not yet been published.

Cullen (1967) obtained a significant fall in intra-ocular pressure in seven eyes of ten patients with chronic simple or secondary glaucoma with high tonometry readings.

The mechanism of this action of clofibrate may be due to its effect on circulating steroid levels, perhaps by altering the mucopolysaccharide in the anterior chamber angle, as postulated by Armaly (1963). It may also be due to the effect on thyroxin levels. McLenachan and Davies (1965) found a history of thyroid disease in 45 out of a hundred patients with open-angle glaucoma and a history of previous illness. It is not clear from their paper whether hypo- or hyper-thyroidism predominated at the time of diagnosis of glaucoma, but they postulate a relationship between thyroid function and the anterior chamber angle mucopolysaccharides.

The hypolipaemic effect of clofibrate is unlikely to be responsible as no definite relationship has ever been shown between serum lipids and chronic glaucoma.

\section{Side-effects}

The drug is well tolerated and safe. Oliver ( 1967$)$ discussed the finding of an average weight increase in a group of $5^{\mathrm{I}}$ patients with ischaemic heart disease who were on clofibrate; this was the only side-effect he encountered. There is no increase in plasma volume or total body water with the drug (Macmillan, Oliver, Simpson, and Tothill, 1965) and it was suggested that the weight increase was due to an increase in adipose tissue. Oliver postulated an increased calorie intake as the cause. No such weight increase has occurred in our patients on clofibrate therapy for diabetic retinopathy; our patients were all on diets, which lends support to Oliver's theory. Clofibrate has a slight laxative effect due to its oily nature but this is not troublesome. One diabetic patient with a long history of drug allergies developed generalized urticaria 24 hours after starting clofibrate; she promptly stopped the drug and her rash cleared. One 40-year-old male with severe diabetic neuropathy developed impotence, which he blamed on clofibrate; however, the impotence cleared up and has not returned despite a second course of clofibrate therapy.

Thus the only side-effect which might genuinely be blamed on clofibrate has been the one case of urticaria in a patient with a history of allergy, and even this has not been proven. 
Because of its mode of action, it is recommended by the manufacturers that hepatic an renal dysfunction and pregnancy be regarded as contraindications to clofibrate therap and that care be exercised in the presence of other anticoagulants.

\section{Summary}

The pharmacology of clofibrate is summarized.

Clofibrate is the treatment of choice in exudative diabetic retinopathy. It is able to reverse the trend towards a steady increase in exudates and it appears logical to use prophylactically in cases showing early exudates, to prevent foveal exudate formation and thus to preserve normal visual acuity. The hard fundus exudates may slowly increase again when therapy is discontinued, but there is no rebound effect. No escape phena. menon has been seen in responsive patients, and resistance to the drug does not seem to develop. Clofibrate has no effect for better or worse on the haemorrhagic element of diabetic retinopathy. Over a 5-year period, its use was accompanied by an improvemene in visual acuity of at least two parameters in 17 per cent. of treated patients as against $\frac{}{3}$ per cent. of control cases.

Non-diabetic hard exudates have also been shown to respond to clofibrate therapy, and further trial is indicated, particularly in Coats's disease and circinate retinopathy. Cases of retinal vascular occlusion in which central vision is still present may also respond; the drug is not of benefit in established cases of vascular occlusion in which central vision has been lost.

Clofibrate is the treatment of choice in xanthomatoses occurring in the presence of raise serum lipids and it is effective in lipaemia retinalis.

Clofibrate causes some lowering of intra-ocular pressure in cases of chronic simplo glaucoma with high tonometry readings and possibly also in other types of glaucoma. cannot be recommended in the treatment of glaucoma in our present stage of knowledg $\overrightarrow{\vec{G}}$ but opens the gate to a new field of research on this subject.

The drug is safe, well tolerated, and easy to take.

\section{References}

ARmaly, м. F. (1963) Arch. Ophthal. (Chicago), 70, 492

BORrIE, P. (1964a) Brit. F. Derm., 76, 53 (1964b) Brit. med. F., 2, I 135

GLEMENTS, D. B., ELSBY, J. M., and SMITH, W. D. (1968) Brit. F. Ophthal., 52, i I I

CHESTER, E. M., and BANKER, B. Q. (1967) Arch. intern. Med., 120, 397

CHURGH, R. E. (1964) Proc. roy. Soc. Med., 57, 45

CULLEN, J. F. (1967) Lancet, 2, 892

and conaGher, w. D. H. (1965) Brit. F. Ophthal., 49, I I

DUNGAN, L. J. P., NOlAN, J., Ireland, J. T., Gullen, J. F., Clarke, B. F., and oliver, M. F. (I9680

Diabetes, $\mathbf{1 7}, 45^{8}$

DUKE-ELDER, S., and DOBREE, J. H. (1967) "System of Ophthalmology", vol. 10, p. $572 . \quad$ Kimptoro

London

haRrold, B. P., and marmion, v. J. (I966) Personal communication

HAYREH, s. S. (1965) Brit. 7. Ophthal., 49, 626

HOUTSMUller, A. J. (1967) Paper read to the VIth Congress of the International Diabetes Federa tion, Stockholm

HUME, R. (1965) Brit. med. J., r, 686

MCLENAGHAN, J., and DAvies, D. M. (1965) Brit. F. Ophthal., 49, 44 I 
MAGMillan, D. C., Oliver, M. F., Simpson, J. D., and tothill, P. (1965) Lancet, 2, 924 MishKel, м. A. (1964) Med. J. Aust., 2, 828

OLIVer, M. F. (1967) Prog. biochem. Pharmacol., 2, 315

ORBÁN, T. (1968) Lancet, x, 47 , hanisch, J., and vereb, K. (1966) Klin. Mbl. Augenheilk., 149, 847

PAtON, A., RUBinstein, K., and Smith, v. H. (1964) Trans. ophthal. Soc. U.K., 84, 559, 564, 58 I ROTH, J. (1969) Brit. 7. Ophthal., 53, 16

VANNAS, S., EsILA, R., and TUOVINEN, E. (1968) Acta ophthal. $(K b h) ., 46,162$

van EGK, W. F. (1959) Amer. J. Med., 27, 196

WAHLIN, R., CRAMER, K.; and HOOD, B. (1964) Svensk. Läk.-Tidn., 6r, 802

woods, A. C., and DUKE, J. R. (1963) Brit. F. Ophthal., 47, 385 